\title{
Utilization of Sewage Sludge after the Process of Autothermal Digestion
}

\author{
Izabela Bartkowska', Lech Dzienis ${ }^{1}$ \\ 1 Bialystok University of Technology, Department of Technology and Environmental Engineering Systems, \\ ul. Wiejska 45 A, 15-351 Bialystok, Poland \\ * Corresponding author's e-mail: i.bartkowska@pb.edu.pl
}

\begin{abstract}
Sediments constitute one of the wastes that are generated in sewage treatment plants. The methods of their final management depend on the sewage sludge system management. One of the employed methods is Autothermal Thermophilic Aerobic Digestion (ATAD). The article presents the process of autothermal oxygen digestion of sewage sludge as a method enabling to obtain biomass, which can be used in the natural environment. In addition to the description of the theoretical basis of the discussed process, the quality of the formed sewage sludge is presented. The amount of sludge and the manner of its final utilisation were also analyzed. The results were presented on the basis of waste records kept in each of the analyzed sewage treatment plants. Sludge transfer cards in 2013-2018 were also analyzed in the sewage treatment plants where sludge undergoes the ATAD process.
\end{abstract}

Keywords: autothermal sediment digestion, ATAD, organic fertilizers, sewage sludge, natural utilisation of sewage sludge.

\section{INTRODUCTION}

Wastewater treatment plants belong to the objects that on the one hand are an essential element of surface water protection, and on the other hand cause a real nuisance to the surrounding environment in terms of air quality, acoustic climate or protection of the Earth's surface. The sewage treatment plant also generates various types of waste, the amount of which depends both on the size of the sewage treatment plant and the technological processes being carried out. The necessity of using highly effective wastewater treatment methods causes the formation of initialand excessive sediments after chemical precipitation and the dosage of an external source of organic carbon, necessary for the implementation of technological processes related to the removal of nitrogen compounds (denitrification).

The amount of sewage sludge is constantly increasing. In 2017 1,035.2 thousand tons of dry matter of sludge were generated in industrial and municipal wastewater treatment plants. Out of this amount, 584.5 thousand tons of dry matter $(56.5 \%)$ were produced in municipal wastewater treatment plants. In agriculture, $26.4 \%$ of municipal sewage sludge was used for land recultivation and composting plant cultivation (GUS (Poland) - Central Statistical Office 2018).

The increasing amount of municipal sewage sludge necessitates the search for the methods of their final utilisation. Two directions are viable: agrotechnical utilization and energy recovery. The utilisation of sewage sludge in soil is possible when it is stabilized and undergoes hygienization. Energy recovery is ensured by combustion or co-incineration processes. Thermal treatment of sludge is associated with high investment and operating costs. Undoubtedly, the preferred way of sludge disposal is its agricultural or natural utilisation. Until now, in terms of sludge hygienization, the most serious limitation of this process was the exceeding of heavy metals concentration (compared to the permissible level) (Podedworna and Heidrich 2010). There are many known methods for processing sewage 
sludge into usable biomass. One of the methods is Autothermal Thermophilic Aerobic Digestion (ATAD). This process, unfortunately still not relatively unknown in Poland, enables to obtain organic fertilizer - instead of waste - in wastewater treatment plants. There are 11 ATAD installations in the country. The purpose of this article was to analyze the amount of sludge generated in these wastewater treatment plants and the manner of its final utilisation. The cognitive goal was also to show that the installations in question enable to obtain the sludge with the desired properties, allowing for its environmentally friendly utilisation. The review will serve to make people aware that the sewage sludge produced in sewage treatment plants should be treated as a source of plant nutrients for recovery, rather than as waste.

\section{Process description}

The ATAD process is based on the natural phenomenon of exothermic organic carbon oxidation under aerobic conditions. An important role is played by microorganisms, owing to which the decomposition of organic compounds contained in the sewage sludge is possible. It generally takes place in two stages. During the first stage, the hydrolysis of complex organic compounds (proteins, carbohydrates and fats) occurs as well as the hydrolysis of cells, when followed by the necrobiosis of microorganisms. These phenomena occur thanks to the participation of extracellular enzymes produced by thermophilic bacteria. During the second stage, thermophilic microorganisms oxidise the products dissolved in water hydrolysis, which turn into low energy compounds. These reactions are accompanied by the release of heat, and the final substances of these transformations are $\mathrm{CO}_{2}, \mathrm{H}_{2} \mathrm{O}$ and $\mathrm{NH}_{3}$ (Ugwuanyi et al. 2008, Zupančič and Roš 2008, Shugen et al.2013).

Efficient heat retention, triggered during decomposition, results in a high working temperature $\left(>50^{\circ} \mathrm{C}\right)$, which in turn results in a high degree of decomposition of organic substances as well as the elimination of pathogens. This process requires initial sludge thickening to about $5 \%$ of dry mass, resulting in a higher unit organic content, which should not be less than $40.0 \mathrm{~g} / 1$, expressed in COD (Bartkowska 2014, 2015). By supplying substrates with appropriate densities, when enough oxygen is supplied in thermally insulated tanks, a spontaneously heated sludge can reach a temperature of $55-80{ }^{\circ} \mathrm{C}$. The process is shown in Figure 1.

The thermophilic population of microorganisms replaces the organisms of the raw sludge. It is a fairly homogeneous microflora, which in more than 95\% consists of Bacillus, Thermus or Actiomycestes bacteria. Most strains belong to the Bacillus stearothermophilus species, which are active in the temperature range of $40-80{ }^{\circ} \mathrm{C}$. The remaining microflora are thermo-tolerant bacteria, which are mesophilic and extremely thermophilic, including the type of Thermus (Piterina et al. 2010a, 2010b). They are usually characterized by the ability to reproduce quickly and the thermophilic cells die off with simultaneously occurring autolysis. In their development, a typical phase of endogenous respiration is not

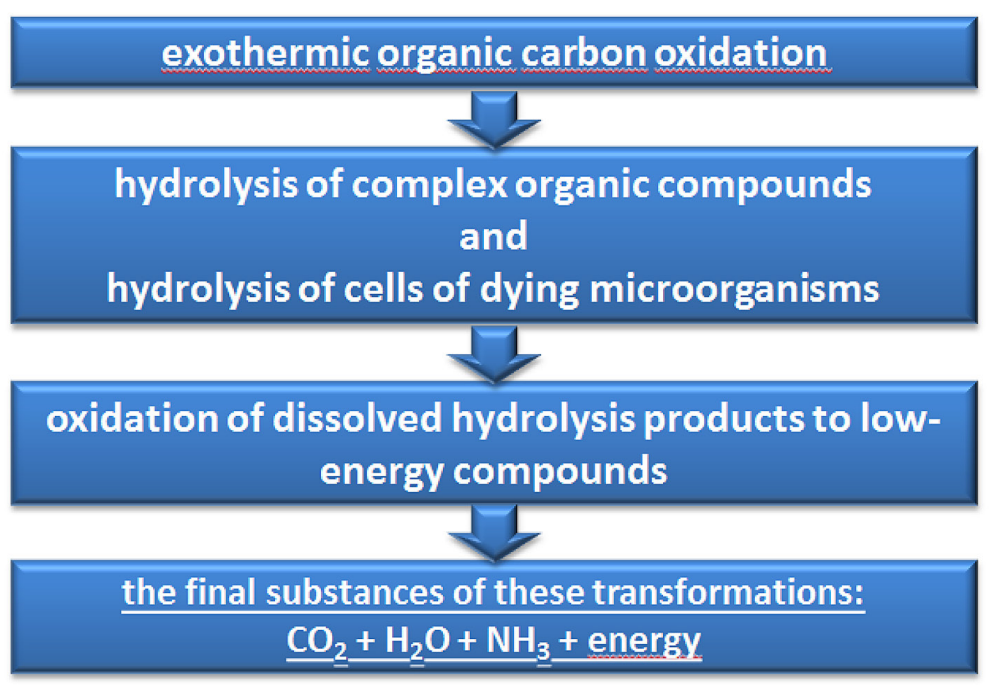

Fig. 1. The autothermal process of thermophilic digestion 
observed. On the other hand, the extracellular thermostable hydrolytic enzymes produced by them are very capable of quick and efficient hydrolysis of proteins, fats, carbohydrates and other organic compounds as well as hydrolysis of dead cells of many micro-organisms (e.g. pathogenic bacteria, yeasts or intestinal parasitic eggs). The fatty acids derived from hydrolysis products are the basic source of carbon and energy for thermophilic bacteria, while amino acids are their main source of nitrogen. These bacteria are also characterized by high resistance to the action of metabolic products and the ability to adapt to small amounts of oxygen. Very rapid increase in the number of thermophilic bacteria, without the need to inoculate sludge with the proper microflora, fast substrate bio-degradation, low sensitivity to temperature fluctuations and resistance to periodic interruptions in system aeration, guarantee, even in emergency situations, an extremely stable and flexible biological system in a thermophilic digestion environment (Rojas et al. 2010, Sokolovs et al. 2015).

\section{Characteristics of sewage sludge}

The dehydrated sewage sludge after the ATAD process has a black-brown earthy form. They are free from unpleasant odours and pathogens. Sludge hydration, depending on the equipment used, ranges from $69.6 \%$ to $82.8 \%$. The ranges of values pertaining to the quality parameters of sludge are presented in Table 1 below.

The analysis of the results obtained during the research on the produced municipal sewage sludge subjected to the ATAD process allowed us to state the obvious fact that the sludge abounds in rich sources of nutrients for plants and substances on which the soil fertility depends. The heavy metals contained in the sludge did not exceed the limit values when they are used for fertilization. Sewage sludge and its microbiological transformation products have a positive effect on the physical, chemical and biological properties of soils. The macro- and micro-nutrients contained in the sewage sludge are well absorbed by plants, and the full-value organic matter accumulated in them contributes to the improvement of the balance of humus compounds. Restoring the components accumulated in sewage sludge to the soil is not only economically appropriate but also necessary to maintain and restore the ecological balance.
Table 1. Physicochemical parameters of sludge after the ATAD process and dewatering

\begin{tabular}{|l|c|}
\hline \multicolumn{1}{|c|}{ Parameter } & Range \\
\hline $\mathrm{pH}$ & $6.5 \div 9.1$ \\
\hline Dry mass [\%] & $15.4 \div 30.5$ \\
\hline Organic substances [\% of dry mass] & $52.1 \div 59.2$ \\
\hline Total nitrogen [\% of dry mass] & $2.4 \div 7.6$ \\
\hline Ammonia nitrogen [\% of dry mass] & $0.8 \div 1.8$ \\
\hline Total phosphorus [\% of dry mass] & $1.1 \div 3.8$ \\
\hline Calcium [\% of dry mass] & $1.6 \div 8.8$ \\
\hline Magnesium [\% of dry mass] & $0.1 \div 1.3$ \\
\hline Cadmium [mg/kg of dry mass] & $0.3 \div 5.5$ \\
\hline Copper [mg/kg of dry mass] & $68.0 \div 806.0$ \\
\hline Nickel [mg/kg of dry mass] & $8.9 \div 59.7$ \\
\hline Lead [mg/kg of dry mass] & $4.7 \div 162.0$ \\
\hline Zinc [mg/kg of dry mass] & $328.0 \div 2396.0$ \\
\hline Mercury [mg/kg of dry mass] & $0.2 \div 9.3$ \\
\hline Chromium [mg/kg of dry mass] & $12.0 \div 448.0$ \\
\hline
\end{tabular}

Source: results of own research carried out in the years 2003-2018.

\section{Research and tests methodology}

The research on municipal sewage sludge was conducted in 2013-2018. The subject of this research was the amount of sludge stabilized in the ATAD installation and dehydrated. The analysis included a summary of data on municipal sewage sludge at 11 treatment plants, a record sheet for municipal sewage sludge and a record sheet for the transfer of sewage sludge. In the case of two wastewater treatment plants, the results of the studies are for a shorter period, as the ATAD installations were built in 2015.

\section{Analysis of results}

All the considered wastewater treatment plants run the ATAD installation. The size of these installations is different, as the average annual mass of produced sludge within the analysed period ranges from 199.9 to $2479.2 \mathrm{Mg}$ (Fig. 2).

In the analysed period, a tendency to increase the amount of sludge was observed in each of the plants. An exemplary graph showing the amount of sludge produced in the years 2013-2018 in one of the analysed plants is shown in Figure 3. The chart shows the trend line for the series of results.

The quantities of sewage sludge produced also change during the year. Figure 4 shows the 


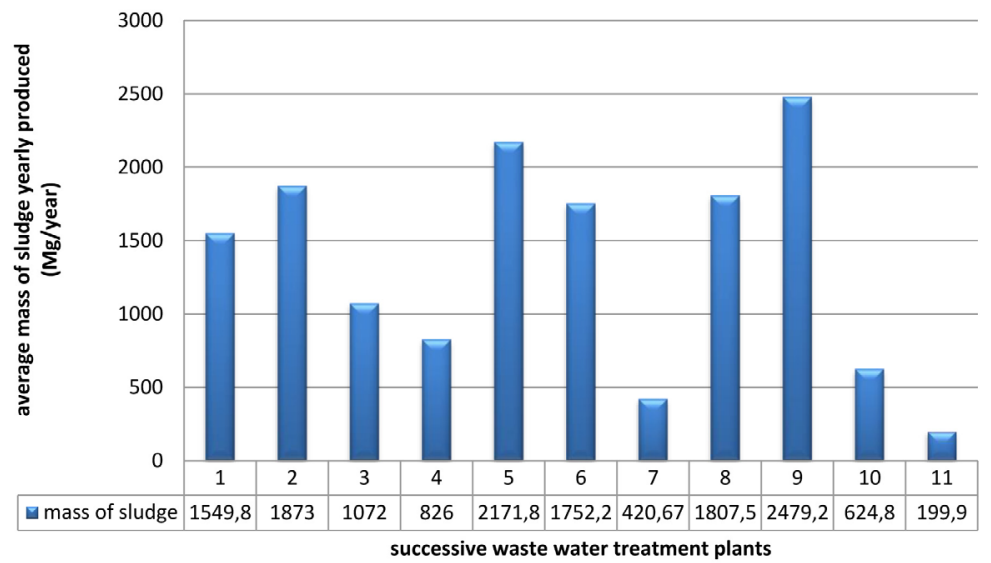

Fig. 2. The mass of sludge generated at the studied wastewater treatment plants

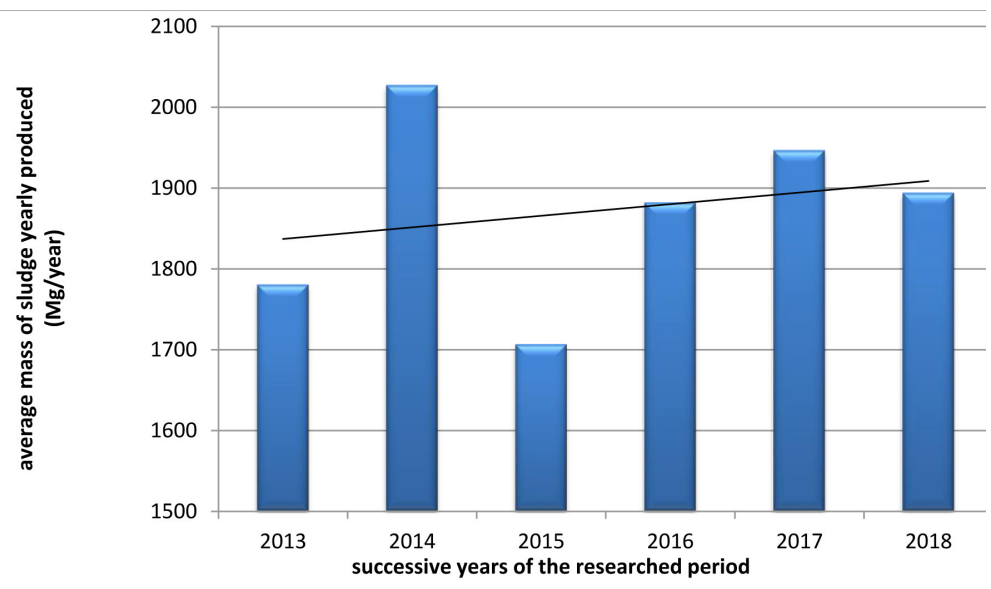

Fig. 3. Example of the amount of sludge generated along with the trend line

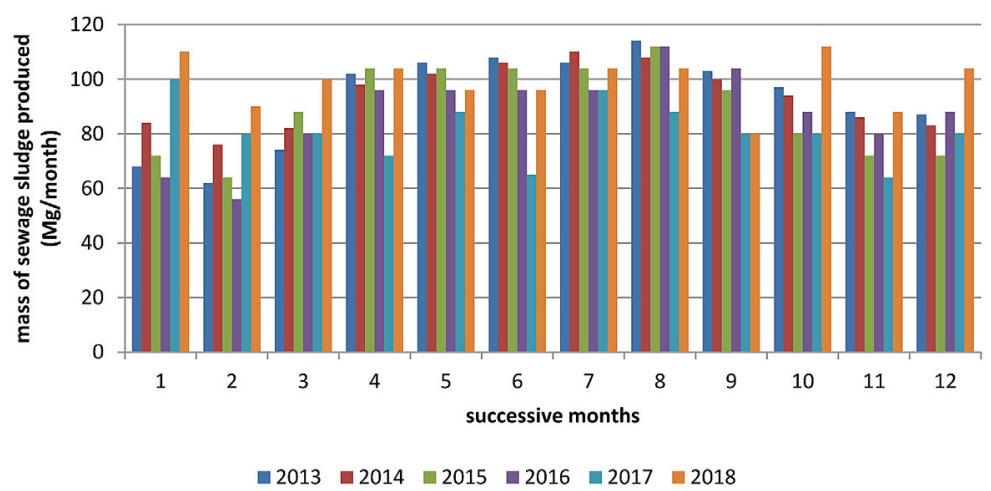

Fig. 4. Monthly quantities of sewage sludge generated in the years 2013-2018

monthly quantities of sewage sludge generated in the years 2013-2018.

The amount of sewage sludge produced within a year is characterised by considerable variability. In the analysed wastewater treatment plants, an increase in their amount was observed from April to August.

\section{Utilisation of sewage sludge generated}

The choice of the final disposal (use) of sewage sludge is a common problem in most Polish wastewater treatment plants. Due to their nature, sewage sludge is subject to many regulations, including legalones, the most important of which are: the Waste Act, the Environmental Protection 
Act, the Regulation of the Minister of Environment on the waste catalogue and the Regulation of the Minister of Environment on municipal sewage sludge.

According to the Waste Act, sewage sludge can be used:

- in agriculture, understood as the cultivation of all commercially marketed agricultural crops, including crops intended for the production of feeds,

- for the cultivation of plants intended for the production of compost,

- for the cultivation of non-food crops and for the production of feed,

- for the recultivation of land, including agricultural utilisation,

- adaptation of land to specific needs resulting from waste management plans, spatial development plans or decisions on development and land use conditions.

When using municipal sewage sludge on the ground, the rate of sludge is determined on the basis of the results of tests of representative samples of municipal sewage sludge and soil samples. When determining the acceptable sludge rate, the principles of good agricultural practice should be taken into account by adapting it in terms of the nitrogen and phosphorus content. The application of a permissible dose on a given soil must not cause the limit values for heavy metals to be exceeded in the surface layer of the soil. Table 2 presents the theoretical size of the area required in relation to the average annual mass of sludge produced in the analysed treatment plants.

Each wastewater treatment plant is obliged to keep records of the sewage sludge produced. Waste transfer cards which include the generated sewage sludge are also catalogued. The generated sewage sludge is used for natural purposes in $95-100 \%$ of the considered plants. On the basis of record cards and transfer cards of municipal sewage sludge, it was stated that the recipients of municipal sewage sludge are the landowners in the area. Sludge is used on medium to heavy soils.

\section{CONCLUSION}

Municipal sewage sludge has high fertilizing and soil-forming properties. The sludge subjected to the process of autothermal thermophilic digestion is also hygienically and sanitarily safe. It should be remembered that the purpose of municipal sewage sludge recovery on the ground surface is to take advantage of the valuable agronomic properties and fertiliser potential of municipal sewage sludge, i.e. the organic matter contained therein and nutrients for plants, such as nitrogen, phosphorus and microelements. However, introduction of these components to the soil, along with the sludge should be in line with the generally binding rules of fertilization, while respecting the principles of environmental protection, including, among others, the protection of soil and water. The determination of the dose and the conduct of studies determining the quality of sludge are extremely important for the fulfilment and preservation of the objective of using municipal sewage sludge in soils. A factor which is indispensable for the utilisation of sludge on the surface is to find willing customers. Landowners should declare the cultivation of crops for which fertilisation with municipal sewage sludge is authorised, have adequate equipment to distribute and mix sludge with soil, and base their actions on the Code of Good Agricultural Practice.

The presented research results, their analysis and evaluation speak in favour of the natural utilisation of sewage sludge after ATAD. This is also evidenced by the decisions to market organic fertilizer from the sludge produced by three of the sewage treatment plants in question.

\section{Acknowledgements}

The research was carried out as part of research work plan WZ/WBiIŚ/2/2019 at the Białystok University of Technology and financed from a subsidy provided by the Minister of Science and Higher Education.

Table 2. Area necessary for the utilisation of the generated municipal sewage sludge

\begin{tabular}{|c|c|c|c|c|c|c|c|c|c|c|c|}
\hline \multirow{2}{*}{ Specification } & \multicolumn{8}{|c|}{ Further wastewater treatment plants } \\
\cline { 2 - 23 } & 1 & 2 & 3 & 4 & 5 & 6 & 7 & 8 & 9 & 10 & 11 \\
\hline Surface (hectare) & 517 & 616 & 357 & 275 & 724 & 584 & 140 & 603 & 826 & 208 & 67 \\
\hline
\end{tabular}




\section{REFERENCES}

1. Bartkowska I., 2014, Influence of the sewage sludge stabilisation process on the value of its oxidation reduction potential. Environmental Technology, Volume 35, Issue 17, 2160-2166.

2. Bartkowska I., 2015, Drop in dry mass and organic substance content in the process of autothermal thermophilic aerobic digestion, Process Safety and Environmental Protection, Volume 98, 170-175.

3. Central Statistical Office, Environmental Protection 2018. (in Polish).

4. Piterina A.V., Bartlett J., Pembroke T.J., 2010a, Evaluation of the Removal of Indicator Bacteria from Domestic Sludge Processed by Autothermal Thermophilic Aerobic Digestion (ATAD), Int. J. Environ. Res. Public Health, 7(9), 3422-3441.

5. Piterina A.V., Bartlett J., Pembroke J.T., 2010b, Molecular Analysis of Bacterial Community DNA in Sludge Undergoing Autothermal Thermophilic Aerobic Digestion (ATAD): Pitfalls and Improved Methodology to Enhance Diversity Recovery, 2, 505-526.

6. Podedworna J., Heidrich Z., 2010, Kierunki ostatecznego ściekowych, Gaz, Woda i Technika Sanitarna, 3, 25-28. (in Polish).

7. Rojas J., Zhelev T., Graells M., 2010, Energy Efficiency Optimization of Wastewater Treatment Study of ATAD, Computer Aided Chemical Engineering, 28, 967-972.

8. Shugen L., Nanwen Z., Ping N., Xudong G., 2013, Semicontinuous Operation of One-Stage Autothermal Thermophilic Aerobic Digestion of Sewage Sludge: Effects of Retention Time, Journal of Environmental Engineering, 139(3), 422-427.

9. Sokolovs A., Grigans L., Dzelzkaleja L., Majore G., Bikulciene L., 2015, Heat recovery technologies from aerobic bio-degradation: from theoretical finding to modeling results, Procedia Computer Science, 77, 141-150.

10. Ugwuanyi J. O., Harvey L. M., McNeil B., 2008, Diversity of thermophilic populations during thermophilic aerobic digestion of potato peel slurry, Journal of Applied Microbiology, 104(1), 79-90.

11. Zupančič G.D., Roš M., 2008, Aerobic and twostage anaerobic-aerobic sludge digestion with pure oxygen and air aeration, Bioresource Technology, 99, 100-109. 